\title{
Vascular disease modeling using induced pluripotent stem cells: Focus in Hutchinson-Gilford Progeria Syndrome
}

\author{
P.R. Pitrez a, b, S.C. Rosa ${ }^{\text {a }}$, C. Praça ${ }^{\text {a, c, d, e }}$, L. Ferreira ${ }^{\text {a, e, * }}$ \\ ${ }^{a}$ CNC-Center for Neurosciences and Cell Biology, University of Coimbra, Coimbra, Portugal

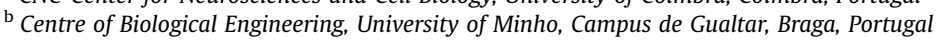 \\ ${ }^{c}$ Faculté des Sciences Jean Perrin, Université d'Artois, Lens, France \\ ${ }^{\mathrm{d}}$ Doctoral Programme in Experimental Biology and Biomedicine (PDBEB), University of Coimbra, Coimbra, Portugal \\ e Institute for Interdisciplinary Research (IIIUC), University of Coimbra, Coimbra, Portugal
}

\section{A R T I C L E I N F O}

\section{Article history:}

Received 28 September 2015

Accepted 2 October 2015

Available online 20 October 2015

\section{Keywords:}

Vascular cells

Induced pluripotent stem cells

Progeria disease

Drug modeling

Drug screening

\begin{abstract}
A B S T R A C T
Induced pluripotent stem cells (iPSCs) represent today an invaluable tool to create disease cell models for modeling and drug screening. Several lines of iPSCs have been generated in the last 7 years that changed the paradigm for studying diseases and the discovery of new drugs to treat them. In this article we focus our attention to vascular diseases in particular Hutchinson-Gilford Progeria Syndrome (HGPS), a devastating premature aging disease caused by a mutation in the lamin A gene. In general, patients die because of myocardial infarction or stroke. Because the patients are fragile the isolation of a particular type of cells is very difficult. Therefore in the last 5 years, researchers have used cells derived from iPSCs to model aspects of the HGPS and to screen libraries of chemicals to retard or treat the disease.
\end{abstract}

(๑) 2015 Elsevier Inc. All rights reserved.

\section{Contents}

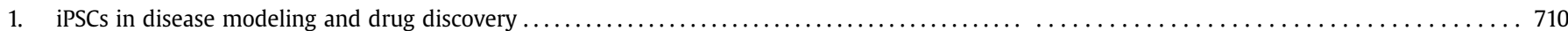

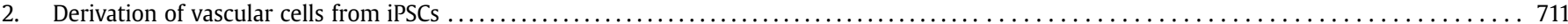

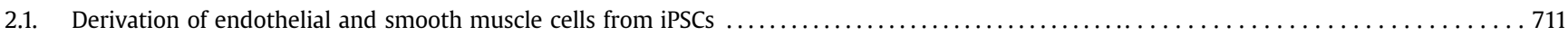

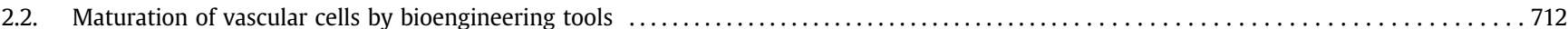

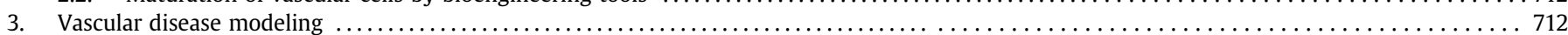

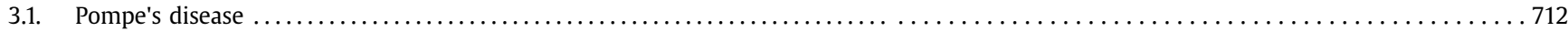

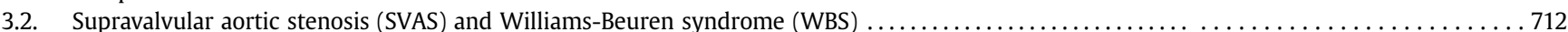

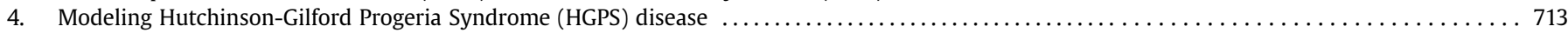

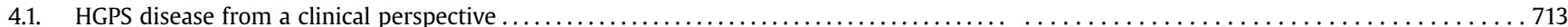

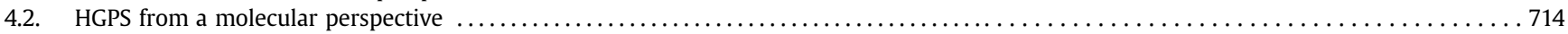

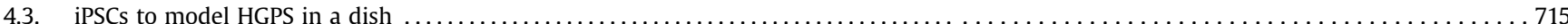

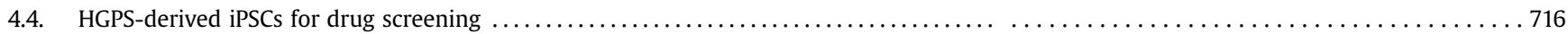

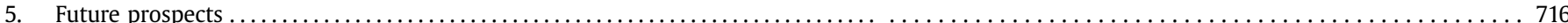

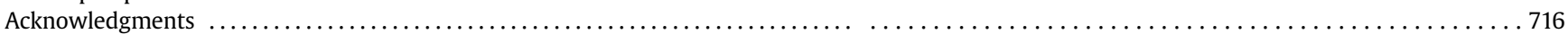

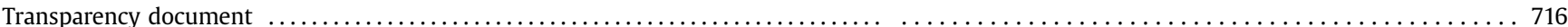

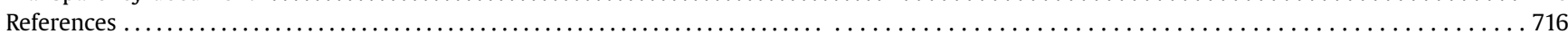

* Corresponding author. CNC-Center for Neurosciences and Cell Biology, University of Coimbra, Coimbra, 3004-517, Portugal.

E-mail address: lino@biocant.pt (L. Ferreira).

\section{1. iPSCs in disease modeling and drug discovery}

In disease modeling and drug discovery programs, cells are an important component of the assay. Although cells isolated from 
patient biopsies or immortalized human-derived cell lines can be used as screening models, their low availability, finite in vitro expansion, genetic and metabolic differences from the original cells, are important limitations. In addition, animal models in particular mouse models have been used to better understand functional changes that can occur in patients with diseases caused from genetic mutations. However mouse models do not always demonstrate the same phenotype as those observed in humans.

iPSCs can overcome some of the limitations observed with animal and adult human cellular models in the field of disease modeling and drug discovery programs. iPSCs are an unlimited source of cells derived from the patient own cells, having the same genetic material, that can be differentiated into the different types of cells affected by a certain pathology. They are of great interest in the study of genetic diseases, in diseases for which access to human tissue is difficult, or diseases that have an important developmental component. In 2008, the first disease-specific iPSCs were derived from somatic cells from a patient with a familiar form of amyotrophic lateral sclerosis (ALS). The patient specific iPSCs were successfully differentiated into motor neurons [1]. At the same time, iPSCs from several patients with a variety of genetic diseases have been generated [2].

The high potential of iPSCs to generate disease models, lead to the creation of several biobanks in USA (Coriell Institute for Medical Research, NIH Center for Regenerative Medicine, ATCC and University owned biobanks), Europe (Cellartis) and Japan (RIKEN Bioresource Center) for storage and distribution of iPSC lines originated from patients and from healthy controls [3]. In the last few years the number of iPSC lines has exploited, and it is expected to increase very rapidly. Indeed, Coriell Institute announced in September 2015, the availability of 300 iPSC lines and the increase of this number to 750 until the beginning of 2016. At the moment there are available approximately 650 iPSC lines from specificdisease patients and healthy controls. Moreover, several largescale iPSC banks are being developed to store and characterize around 10,000-20,000 high quality iPSC lines in the next years [3]. Currently, there are at least 50 diseases that can be model through iPSCs and they can be assembled, among others, in neurological, cardiovascular, hepatic, hematopoietic and respiratory disorders $[4,5]$. In the case of cardiovascular diseases it is already possible to modulate a minimum of 11 diseases from several iPSC lines [6-8].

The goal of this review is to highlight recent advances in the derivation of vascular cell models for drug discovery and disease modeling, in particular the ones derived from HGPS. A review in this topic of research is justified by recent advances (last 5 years) in the derivation of vascular cells with a more precise phenotype [9-13], the identification of the signaling pathways involved in the specification of iPSCs into vascular cells $[9,14,15]$, the development of bioengineering tools to mature iPSC-derived vascular cells [16-21] and the use of iPSCs to model HGPS disease [21-23].

\section{Derivation of vascular cells from iPSCs}

\subsection{Derivation of endothelial and smooth muscle cells from iPSCS}

To develop pluripotent stem cell (PSC)-derived models of human vascular diseases it is crucial to establish efficient differentiation, expansion and purification protocols to obtain functional cells. Differentiation of iPSCs into vascular lineages is a multistep process that involves mesoderm formation, differentiation and specification of vascular progenitors and their functional maturation (Fig. 1). Early differentiation of human PSCs is modulated by major signaling pathways: bone morphogenetic protein (BMP), transforming growth factor (TGF)- $\beta /$ Activin/Nodal, WNT/ $\beta$-catenin and fibroblast growth factor (FGF) [24] giving rise to cardiovascular lineage progenitors which can be differentiated into cardiomyocytes, endothelial cells (ECs) and smooth muscle cells (SMCs).

The main strategies for deriving SMCs and ECs from human PSCs are: through embryoid bodies (EBs) formation in medium enriched serum $[25,26]$, through monolayer formation (both of these methods can be combined with the sequential addition of factors important for SMCs or ECs derivation) and through co-culture with stromal feeder cells (OP9, S17 or M210B4) [14]. Additionally, studies reporting serum-free and chemically defined methods for generating SMCs [9] and ECs $[10,27]$ have been published recently. In addition, the derivation of both ECs and perycites from iPSCs has been also documented [10].

PDGF-BB/PDGFR- $\beta$ axis, TGF- $\beta$ signaling pathway, retinoic acid (RA) and $\mathrm{Wnt} / \beta$-catenin signaling have been shown to be

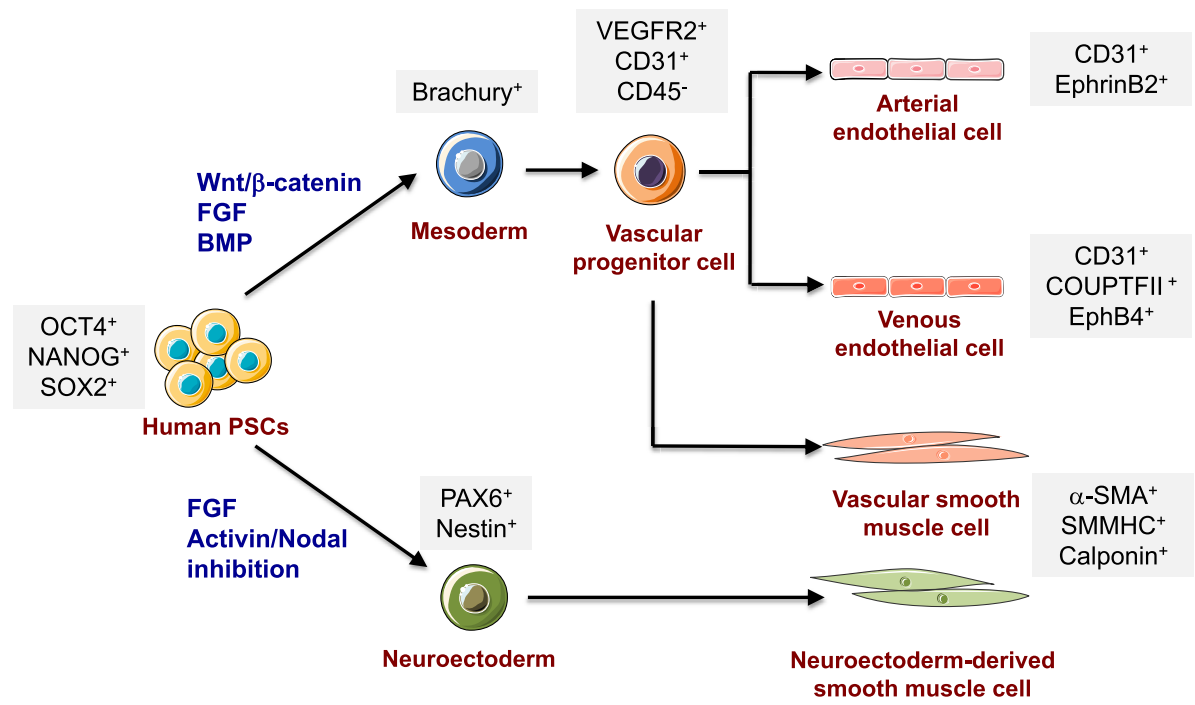

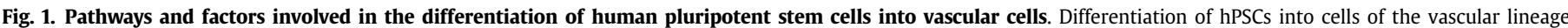

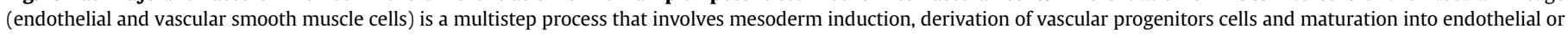
smooth muscle cells. 
important for the differentiation of human PSCs into SMCs [14]. FGF2 and BMP4 are two key signaling pathways important not only for mesoderm formation $[14,28]$ but also for it specification to the ECs lineage [14,29]. Another key regulator of vasculogenesis and endothelial differentiation is vascular endothelial growth factor (VEGF), the presence of this factor increases the percentage of human PSC-derived ECs, probably through the regulation of survival and propagation of ECs [14]. The small molecule SB431542, a TGF- $\beta$ inhibitor has been shown to increase the yield of ECs from human embryonic stem cells (hESCs) [15]. SMCs have a spindle-like morphology, express SMC-specific contractile proteins such as $\alpha$ smooth muscle actin ( $\alpha$-SMA), smooth muscle myosin heavy chain (SMMHC), calponin, smooth muscle protein $22 \alpha$ (SM $\alpha-22)$, calmodulin and h-caldesmonin. An important hallmark of SMCs functionality is contractility response after stimulation [25]. ECs have a cobblestone-like morphology and express CD31/PECAM1, CD34, VEFGR1/Flt1, VEGFR2/Flt2, CD144/VE-Cadherin, CD106/ Vascular Cell Adhesion Protein (VCAM1), eNOS, von Willebrand Factor (vWF), among other markers. Functionally these cells are able to uptake acetylated low-density lipoprotein and generate tube-like structures within Matrigel [25].

Studies have shown that SMCs present in different heart vessels have a distinct embryologic origin, which can result in lineage specific differences in growth, gene expression and function. This diversity may help to explain different patterns of vascular disease, namely differences in susceptibility to atherosclerosis and vascular calcification [9]. A protocol to derive SMCs from neuroectoderm, paraxial mesoderm and, lateral plate mesoderm has been reported [9] (Fig. 1). In this regard the use of appropriate origin-specific SMCs is vital for accurate disease modeling and therapeutic discovery. Similarly to SMCs, ECs also develop distinct gene and protein expression depending on the embryological origin and environmental cues (arterial, venous and lymphatic vessels) [30]. Progenitor ECs are specialized to acquire arterial, venous and bloodforming hemogenic phenotypes, these processes require several key regulatory signals (reviewed in Ref. [31]). Several factors have been shown to be important for the arterial-venous specification: hemodynamic forces [32], Ephrin family of receptor tyrosine kinases, Notch signaling, and chicken ovalbumin upstream promotertranscription factor II (COUPTFII), among others [31]. In recent studies human PSCs-derived ECs have been also characterized for specific markers of arterial and or venous sub-phenotype $[10,12,33]$. However, further progresses are needed for a full control of endothelial cell sub-phenotypes.

\subsection{Maturation of vascular cells by bioengineering tools}

In some cases, the use of synthetic extracellular matrixes (ECM) in combination with iPS-based cells may be important to induce the maturation of vascular cells. For example, human PSCs-derived SMCs were seeded in fibrin gels and the ECM induced the expression of adhesion molecule genes towards the expression observed in mature human vascular SMC [26].

Besides ECM, flow may be an important tool to mature vascular cells derived from iPSCs. In vivo, arteries and veins show different phenotypic characteristics [34]; this probably results from the sum of intrinsic genetic differences and exposure to different hemodynamic forces. It was been shown that flow has an important role in arterial-venous specification [32]. ECs derived from iPSCs were specified into the arterial sub-phenotype by culture in a biomimetic flow reactor under arterial flow shear stress that increased the expression of arterial-related markers, EphrinB2, CXCR4, Connexin40 and Notch1 [18]. Interestingly, both low (5 dyne $/ \mathrm{cm}^{2}$; typically found in venous vessels) and high (10 dyne $/ \mathrm{cm}^{2}$; typically found in arterial vessels) shear stress up-regulated the expression of EphB2 an arterial marker [18].

Shear stress also modulates the functional activity of ECs derived from PSCs [35]. When these cells were cultured under arterial flow shear stress conditions, they were more resistant to inflammation after exposure to tumor necrosis factor (TNF)- $\alpha$ than cells cultured under static conditions [35]. In addition, iPSCsderived ECs presented an up-regulation of transcription factors kruppel-like factors 2 and 4 (KLF2 and KLF4) indicative of a functional vasoprotective phenotype, typical of a large artery endothelium [18]. Moreover, iPSCs-ECs were able to adopt an atherosclerosis phenotype when cultured for $72 \mathrm{~h}$ under an atheroprone flow shear stress [36].

\section{Vascular disease modeling}

According with the World Health Organization, cardiovascular disease is the leading cause of mortality worldwide, representing approximately $31 \%$ of all global deaths. Therefore, in vitro models able to reproduce at some extent the disease in a dish may be an important tool to study the disease and to discover new therapeutic agents [6]. iPSCs have been used to model Pompe's disease, supravalvular aortic stenosis (SVAS), Williams-Beuren syndrome (WBS) and HGPS. In this section we summarize the advances in modeling Pompe's disease, SVAS and WBS by iPSCs, while in section 4 we review the most significant progresses in the use of iPSCs to model HGPS.

\subsection{Pompe's disease}

Pompe's disease also known as glycogen storage disease type II, results from a mutation in the acid $\alpha$-glucosidase (GAA) gene, which encodes the lysossomal glycogen-degrading enzyme leading to the accumulation of glycogen in different tissues, namely skeletal, smooth muscle and cardiac tissue [37] and vascular endothelium $[38,39]$. Therapies based in enzyme replacement have shown success in extending patient survival; however, the therapeutic efficacy in skeletal muscles is not yet satisfactory. Pompe's diseaseinduced iPSCs have been generated from patients with infantiletype [40] or late-onset-type Pompe's disease [41]. Undifferentiated cells showed the expression of pluripotent markers but low GAA activity and high glycogen content. Treatment of these undifferentiated iPSCs with recombinant GAA reduces significantly the number of glycogen granules [41]. Since the heart is one of the most affected organs in Pompe's disease, cardiomyocytes have been derived from Pompe's disease-induced iPSCs [40]. These cells presented low oxygen consumption and low extracellular acidification rates, high levels of glycogen and several ultrastructural alterations, such as deteriorating mitochondria and autophagosome-like structures. Interestingly, treatment with L-carnitine was able to ameliorate the oxygen consumption rates. By comparative analysis, the authors identified several genes related with glycogen metabolism, lysosome and mitochondria, which can be used as targets for drug testing [40].

\subsection{Supravalvular aortic stenosis (SVAS) and Williams-Beuren syndrome (WBS)}

SVAS results from mutations in elastin gene. The disease is characterized by abnormal proliferation of SMCs that induces tightening or obstruction of the ascending aorta and other arterial vessels [42]. Individuals with WBS also display the same cardiovascular manifestations as observed in SVAS. Both diseases are categorized as elastin arteriopathies. Genetically modified mice have been used to elucidate the pathophysiology of the disease; however, the homozygous-null mice die after birth [43]. In 
addition, some inter-species differences in the splicing of elastin gene may also interfere with the study of the disease. Therefore, human iPSCs have been derived from a patient with SVAS [42] and another with WBS [44]. SMCs derived from SVAS-iPSC lines had less organized networks of muscle $\alpha$-actin filament bundles which could be rescued by exogenous expression of elastin recombinant protein or by boosting small GTPase RhoA signaling. The derived SMCs also migrate more to platelet-derived growth factor (PDGF) and show higher proliferation rates, which require elevated activity of extracellular signal-regulated kinase 1/2 [42]. SMCs derived from WBS-iPSCs present low levels of elastin mRNA and protein, high proliferative capacity, low expression of SMCs late markers, reduced calcium flux, impaired response to vasoactive agents and vascular tube formation [44]. Importantly, treatment with synthetic elastin-binding protein ligand 2 partially rescues the phenotype and rapamycin, a mTOR inhibitor, was able to reduce the proliferation rates and to improve the differentiation and vascular tube formation of the cells.

\section{Modeling Hutchinson-Gilford Progeria Syndrome (HGPS) disease}

\subsection{HGPS disease from a clinical perspective}

HGPS was first described by Jonathan Hutchinson in 1886 [45] and then by Hastings Gilford in 1897 [46]. Progeria is a rare and fatal genetic condition, characterized by premature aging symptoms in children [22,23,47-49] and it affects approximately 1 in 4-8 million newborns almost equally in both sexes (1.2:1 male to female ratio) and all races [48,49]. Up July 2015, 125 children have been diagnosed with Progeria in 43 different countries [50]. Yet, according to Progeria Research Foundation, it is believed that there is more 350-400 children worldwide living with Progeria which has not yet been diagnosed or identified [50].

Individuals with HGPS appear to show aging-related phenotypes at a much faster rate than normal, leaving young children with the appearance and health conditions of an aged individual $[48,49]$. This syndrome causes changes in various organs and systems such as the skin, skeleton, hair, body fat and cardiovascular system [48]. Unexpectedly, it has been demonstrated that normal aged individuals also shown accumulation of progerin, suggesting that a HGPS model could also be useful as a model for normal aging $[48,51]$. Indeed, similarities between HGPS and natural aging have been reported [48,51-53]. Nevertheless, one independent progeroid syndrome cannot recapitulate all clinical and physiological alterations that are observed in physiological aging [51,54,55]. For instance, cancer, Alzheimer's disease, and various other pathological conditions of aging are absent in HGPS [55,56]. Some clinical characteristics accelerated in HGPS are common to both HGPS and physiological aging, namely progressive vascular disease, bone loss (osteopenia or osteoporosis), loss of subcutaneous fat, hair loss and also progerin accumulation [55,57]. Additionally there are certain cardiovascular alterations in HGPS that are similar to arteriosclerosis of aging, such as hypertension, vascular stiffening, vascular calcification, plaque formation despite normal cholesterol levels, and also stroke and heart attacks [51,53,55]. Cellular elements and cardiovascular alterations in HGPS and physiological aging are summarized in Table 1.

Most of the children with Progeria have a normal appearance in the first few months after birth; however after 18-24 months of age, or even early, the child starts to exhibit many characteristics of accelerated aging [58]. The mean age of diagnosis is 2.9 years, generally following a fall-off from the growth curves, loss of scalp hair (40\%), scleroderma-like focal changes (28\%), lipodystrophy (20\%), and the appearance of characteristic facial dysmorphic traits, including a characteristic visible vein across the nasal bridge $[49,59]$. Other clinical characteristics also include alopecia (loss of hair), kidney failure, loss of body fat, prominent eyes and scalp veins, osteoporosis among others [47,48,58].

The majority of children with HGPS die from complications of atherosclerosis, in which myocardial infarction and stroke represent the most frequent cause of death at a mean age of 13 years $[55,60]$. In fact, both myocardial infarction and stroke are responsible for at least $90 \%$ of patient's death [52]. One of the hallmarks of the disease is the loss of SMCs in large arterial vessels [51,61,62], making the blood vessels an important target in Progeria. The

Table 1

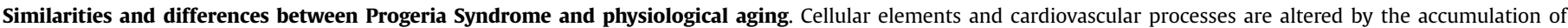
progerin in HGPS and in physiological aging $[51-55,87,88]$.

\begin{tabular}{|c|c|c|c|}
\hline & Similarities & Differences & \\
\hline $\begin{array}{l}\text { Cellular } \\
\text { elements }\end{array}$ & 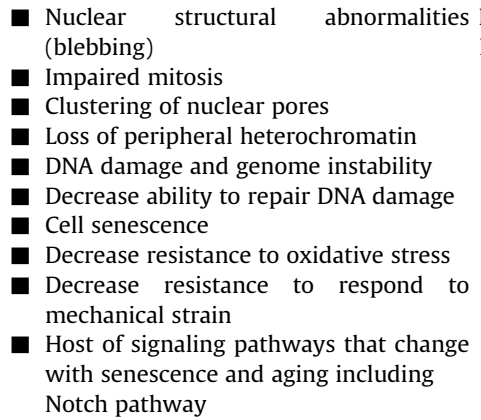 & $\begin{array}{l}\text { HGPS } \\
\text { High levels of progerin accumulation } \\
\mathbf{0} \text { Delayed cytokinesis } \\
\mathbf{0} \text { ROS increase } \\
\mathbf{\square} \text { Disregulated mitochondrial function } \\
\mathbf{\square} \text { Disregulated protesome activity } \\
\end{array}$ & $\begin{array}{l}\text { Physiological Aging } \\
\text { Low levels of progerin/Pre-lamin A accumulation } \\
\boldsymbol{\square} \text { Thickening of nuclear lamina } \\
\text { Oxidative damage } \\
\boldsymbol{\square} \text { Histone modifications }\end{array}$ \\
\hline $\begin{array}{l}\text { Cardiovascular } \\
\text { alterations }\end{array}$ & $\begin{array}{l}\text { Arteriosclerosis (premature in HGPS } \\
\text { patients) - calcification, inflammation } \\
\text { and evidence of plaque erosion or } \\
\text { rupture } \\
\text { - Vascular dysfunction } \\
\text { - Hypertension } \\
\text { - Vascular stiffening } \\
\text { - Vessel wall remodeling with abnormal } \\
\text { ECM } \\
\text { - Myocardial infarction } \\
\text { - Stroke }\end{array}$ & $\begin{array}{l}\text { vSMC depletion, particularly in the aortic media } \\
\text { Adventitial fibrosis } \\
\text { Impaired coronary function } \\
\text { Normal intima-media thickness of the carotid ar- } \\
\text { tery, as are cholesterol, low-density lipoprotein } \\
\text { (LDL), and high sensitivity C-reactive protein levels }\end{array}$ & $\begin{array}{l}\text { Atherosclerosis (intima-medial thickening, } \\
\text { atherosclerotic plaque, inflammation and } \\
\text { endothelial destruction, proliferating medial } \\
\text { SMC) }\end{array}$ \\
\hline
\end{tabular}


reason for SMC loss is unknown. Some post-mortem studies in HGPS patients have revealed a calcified focal plaque throughout large and small arteries and the vascular media no longer contained SMCs, particularly in the aortic media, which appeared more susceptible to hemodynamic and ischemic stress [54,62]. The SMCs were replaced with ECM or fibrous tissue, and the elastic structure of the vascular media was destroyed [55,62].

\subsection{HGPS from a molecular perspective}

The nuclear lamina in mammalian cells is a thin $(20-50 \mathrm{~nm})$ protein meshwork that interacts with various proteins, including lamins A, C, B1 and B2 [58,63]. The integrity of nuclear lamina is crucial not only for maintaining the nuclear shape and structure, but also for transcriptional regulation, nuclear pore positioning and function, and heterochromatin organization [48,55,64]. Nuclear lamina is required for most nuclear activities, such as DNA replication, cell cycle regulation and nuclear positioning within the cell $[63,64]$. The lamins are the products of three genes: LMNA, encoding lamins $A, A \Delta 10, C$ and $C 2$; LMNB1, encoding lamin B1; and LMNB2, encoding lamins B2 and B3 $[48,63]$. However, the major isoforms expressed in all differentiated cells in vertebrates are lamin A and lamin C [48]. Mutations in LMNA, LMNB1 and LMNB2 are responsible for a group of genetic disorders named laminopathies $[48,58,63]$. Over 180 mutations in these genes are associated with at least 13 known laminopathies [63].

HGPS is a laminopathy typically caused by a single point mutation of the LMNA gene that encodes the major components of the nuclear lamina, the lamins A and C $[65,66]$. Although six different mutations have been reported to cause HGPS, approximately $90 \%$ of the cases are caused by a de novo C-to-T substitution at position 1824 of LMNA, G608G mutation (a change from glycine GGC to glycine GGT, referred to as G608G) $[48,60,63]$. This autosomaldominant mutation activates a cryptic splice donor site, creating an mRNA that is missing 150 nucleotides. This is translated into a protein termed 'progerin', which contains a 50 amino-acid internal deletion. It is important to note that the disease phenotype is not caused by the reduction of lamin $A$, but due to the production of progerin, being HGPS a dominant negative disease [55,57,67]. This was proved using a mouse model entirely lacking lamin A ( $\mathrm{Lmna}^{-}$ ${ }^{-}$) and showing no signs of disease [55].

Lamin $A$ is normally produced from a precursor molecule (prelamin A) via a series of four major post-translational processing steps, which begins at the C-terminal end. This C-terminal tail contains a $\mathrm{CaaX}$ motif, where the $C$ is a cysteine, the $a$ residues are 2 aliphatic amino acids, and the $X$ can be any aminoacid. First, prelamin $\mathrm{A}$ is modified by farnesylation (by farnesyl transferase), where a farnesyl group is linked to cysteines of C-terminal CaaX boxes binding the normal and mutant lamin $A$ to the nuclear membrane. Following farnesylation, the last three amino acids $(a a X)$ are cleaved by a zinc mellatoprotease, ZMPSTE24 (mouse) or FACE-1 (human). Then, methylation of the C-terminus by isoprenylcysteine carboxyl-methyl transferase (ICMT), and internal proteolytic cleavage occurs. Removal of the last 15 coding amino acids again by ZMPSTE24, along with the CaaX box and farnesyl group generates mature lamin A with 646 amino acids (Fig. 2) $[22,48,55,68]$. After these modifications, normal lamin A is released from nuclear membrane, but in HGPS, progerin remains anchored to the inner nuclear membrane [59]. Actually, the first three steps of the post-translational maturation can be performed in HGPS. However, the fourth step doesn't occur since HGPS prelamin A lacks 50 amino acids near the C-terminal missing the site for endoproteolytic cleavage of the final 16 amino acids (Fig. 2). Thus, progerin is shortened and farnesylated which results in permanent progerin intercalation within the nuclear membrane, causing a disruption in the nuclear lamina integrity and structural stress on the nucleus [47,48,68-70], which leads to a number of abnormalities in nuclear structure and function. Progerin alters the nuclear shape and size and HGPS cells present blebbing of the nucleus, disrupted mitosis, and altered gene expression. Also, the nucleus presents wrinkles, a thick nuclear lamina, disorganized heterochromatin and consequently premature senescence.

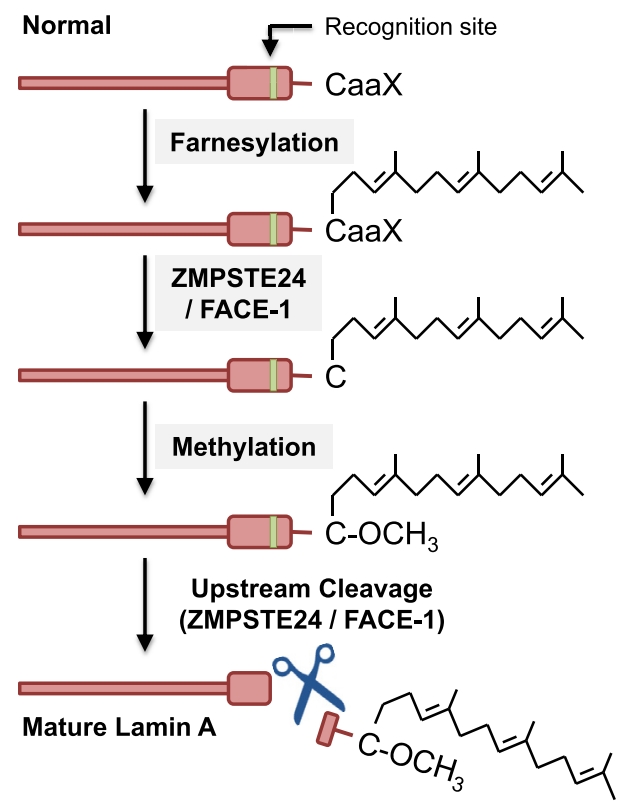

HGPS

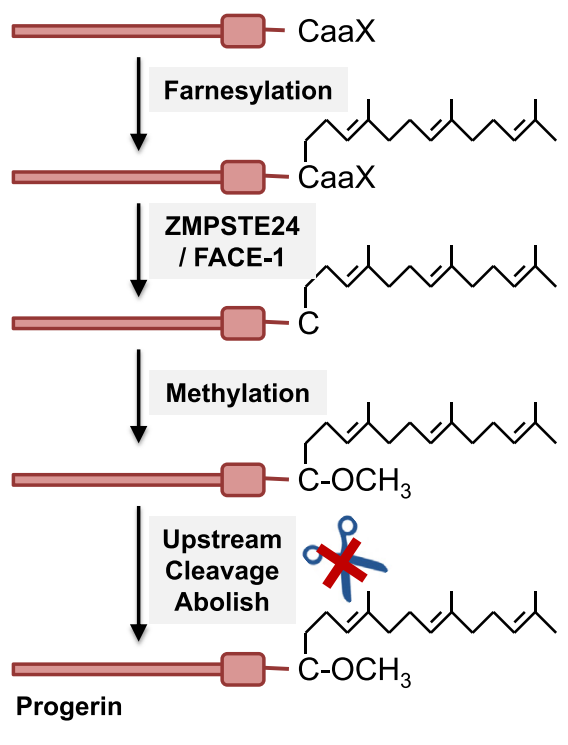

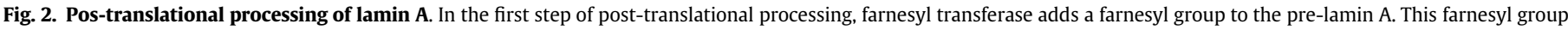

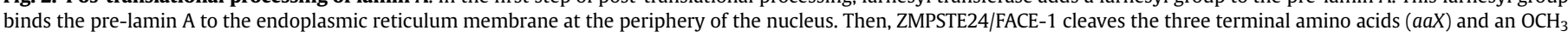

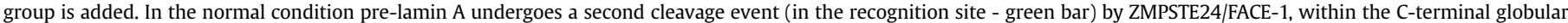

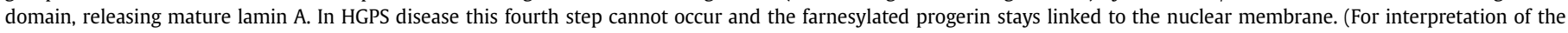
references to color in this figure legend, the reader is referred to the web version of this article.) 


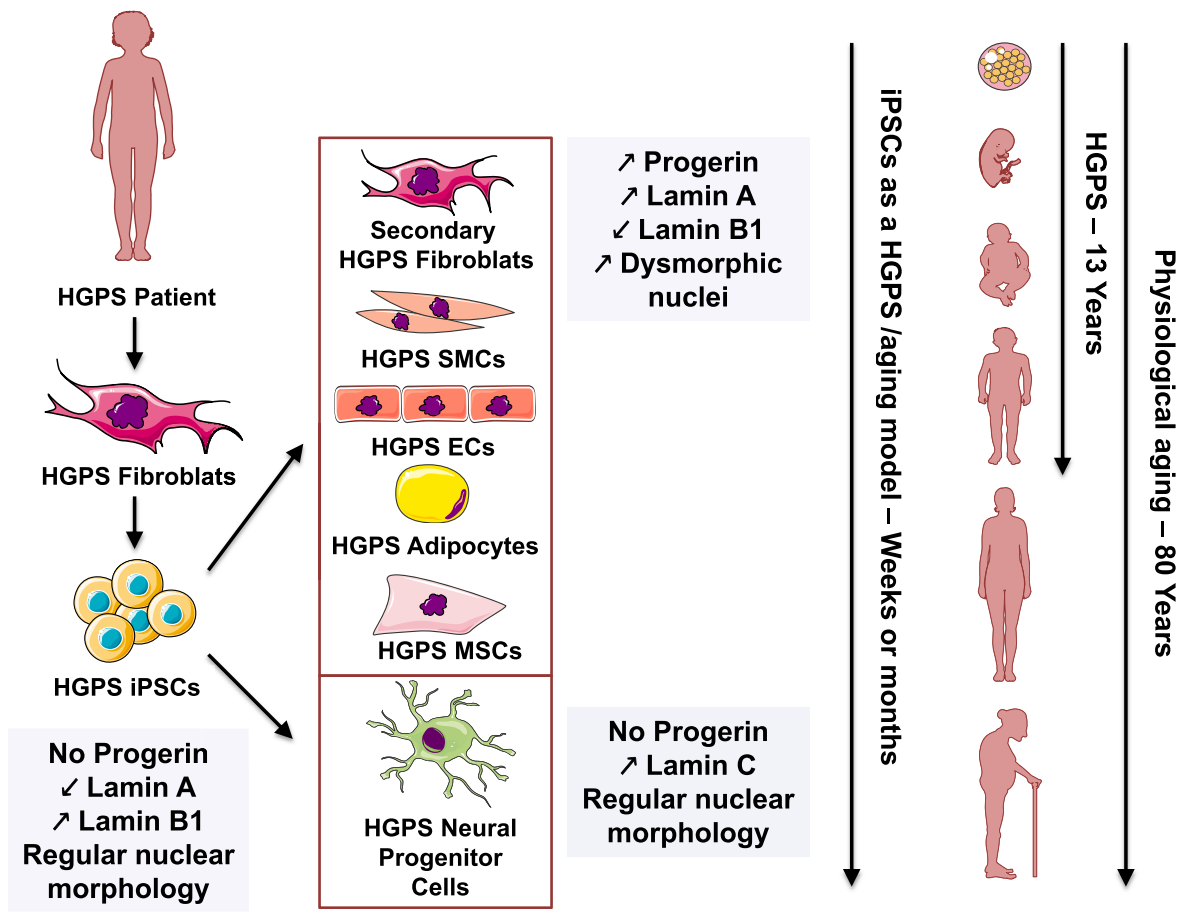

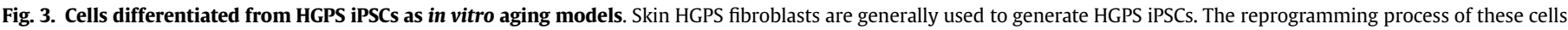

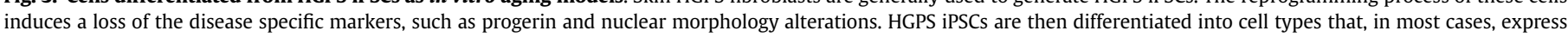
progerin and have significant nuclear morphology alterations. These cells may be an important biological resource to study human aging.

\section{3. iPSCs to model HGPS in a dish}

All the symptoms observed in HGPS patients cannot be entirely recapitulated in mouse models [22]. Much of the knowledge that we have today about HGPS pathologies came from studies using patient skin fibroblasts and cell lines that ectopically express progerin [71]. Yet, it is important to note that tissue-specific cell lines from HGPS patients are not easily obtained due to the difficulty of performing biopsies on fragile patients [72]. Therefore, iPSCs derived from HGPS skin fibroblasts might help to study the disease in cell types that are not easily accessible in HGPS patients such as neural cells, SMCs, among others $[22,23,73,74]$. In this section we will focus our attention in the major findings about HGPS pathology mechanisms that were identified using cells derived from HGPSiPSCs.

Studies have shown that the efficiency of iPSCs derivation from HGPS cells is lower than in normal cells $[22,75]$. HGPS iPSCs presented low expression of lamin $\mathrm{A} / \mathrm{C}$ (and thus progerin) in the pluripotent state, which explains the absence of a Progeria phenotype during the early developmental period of HGPS patients (Fig. 3) [21,76,77]. Interestingly, the silencing of LMNA gene transcription in iPSCs lead to an up-regulation of lamin B1, which seems to indicate that a certain expression of lamin proteins is needed for survival/activity of the cells [78]. HGPS iPSCs have nuclear morphology, pluripotency, epigenetic and transcriptional profiles similar to healthy iPSCs $[75,76]$.

The differentiation of HGPS iPSCs into different cells such as adipocytes [78], fibroblasts [22], mesenchymal stem cells (MSCs) [22], ECs [22,79], SMCs $[22,73]$ but not in neural progenitors $[22,23]$ leads to the expression of progerin (Fig. 3). The differentiated cells showed nuclear dysmorphology, cell growth retardation, susceptibility to apoptosis, DNA-repair defects, mislocalization of the protein LAP2 (lamin-associated polypeptide 2) and reduced telomere length. Each differentiated cell recapitulates many hallmarks of the disease. For example, adipocytes derived from HGPS-iPSCs showed a harsh lipid storage defect [78].

Some aspects of the disease were only possible to evaluate using HGPS iPSCs. For example, studies have shown that MSCs derived from HGPS-iPSCs are much more sensitive to hypoxia than normal MSCs [22]. Also adipocytes differentiated from MSCs had lipid storage defects at late differentiation stage due to the inhibition of transcription activation of PPAR $\gamma 2$ and C/EBP $\alpha$ [78]. Moreover, HGPS iPSCs have been very useful tool to study in vitro the pathology related to vascular cells. Human HGPS iPSC-derived ECs have been used to study the potential mechanism of cell loss under flow conditions, more specifically the involvement of transient receptor potential (TRP) channels [79]. Up-regulation in the expression of vanilloid TRP-2 induces hypotonicity in HGPS iPSCECs under mechanical stress, due to an increase in cytosolic $\mathrm{Ca}^{2+}$. This might explain the mechanical stress-induced vascular cell death in HGPS patients [79]. In a separate study, it was found that DNA-dependent protein kinase catalytic subunit (DNAPKcs) was a downstream target of progerin in SMCs differentiated from HGPS iPSCs [73]. It was also shown that the expression of SMMHC, a marker for fully differentiated SMCs, was not up-regulated in HGPS SMCs, which suggested a delay in the terminal differentiation program of these cells [21]. Interestingly, the accumulation of progerin stimulated a down-regulation of poly (ADP-ribose) polymerase 1 (PARP1), resulting in prolonged mitosis of HGPS SMCs [21]. This down-regulation of PARP1 was also detected in primary skin fibroblasts from HGPS patients and in late passages of cells from a G608G transgenic animal model [21], clearly demonstrating that PARP1 is a regulator of SMCs and other cell types survival in HGPS [21].

Although the expression of progerin could be reactivated after the iPSCs differentiation in almost all types of cells, this did not happen in neural progenitor cells (Fig. 3) [23]. Indeed, this protection of neural cells in HGPS recapitulates what happens in vivo, 
since HGPS patients do not present cognitive issues [23,68]. Therefore, differentiation studies of HGPS-iPSCs into neural progenitor cells contributed for our knowledge about the molecular mechanisms underlying this process. It was found that miR-9 negatively controlled lamin A and progerin expression in neural cells, being the main cause for neural cells preservation in HGPS [23]. These results have been also validated in $\mathrm{Lmna}^{-1-}$ mice [80]. Lamin $C$ was abundant in mouse brain but not lamin A or its precursor prelamin A.

\subsection{HGPS-derived iPSCs for drug screening}

Before iPSC technology, the study of new treatments was limited to patients' primary fibroblast cultures and genetically modified healthy cells over-expressing progerin [57,81]. Nevertheless, cells derived from HGPS iPSCs offer a platform for pharmacological studies and effective chemical compound search through drug screening [82]. The correction of LMNA mutation in HGPS cells reverts the phenotype of the cells [83] and this type of approach can be used to generate genotype matched cell lines for disease modeling and drug discovery and potentially in therapeutics.

Some studies have used HGPS-derived iPSCs for drug screening. For example, drugs currently used in clinical trials for HGPS patients have been tested in HGPS iPSC-derived cells [82]. MSCs derived from HGPS iPSCs were used to verify some molecular parameters and to quantify functional defects of the cells in the presence of drugs [82]. Farnesyltranferase inhibitor (FTI), rapamycin and the combination of zoladronate acid and pravastatin (ZoPra) decreased the nuclear shape abnormalities and the premature osteogenesis in the derived MSC [82]. This study also evaluated the effect of the different drug combinations, showing no additional benefits compared with single-drug treatments [82]. Although limited number of combinations has been tested, the study opened the possibility of using HGPS iPSCs for highthroughput drug screening.

\section{Future prospects}

iPSCs offer the possibility to study HGPS disease at levels not possible before. The possibility of generating cells of different tissues that are very difficult to obtain from HGPS patients is very important to study the disease at different tissues. This is the case of vascular cells, neural cells, among others as well as stem/progenitor cells. Only now, the mechanisms underlying the vulnerability of SMCs in HGPS patients have been identified [21]. However, further research is needed to investigate the reasons behind SMC loss under arterial flow.

So far, there is no cure for HGPS. The HGPS iPSCs technology in combination with high-throughput screenings may be also used to identify drugs that interfere with the expression, splicing, farnesylation, and function of progerin [75]. Some treatments have been already tested in HGPS patients to retard the progression of the disease [48,54,59]. From 2007 to 2009, the farnesyl transferase inhibitor Lonafarnib was administrated to 25 HGPS children in the first therapeutic trial in Boston (ClinicalTrials.gov Identifier: NCT00425607) [84]. One of the outcomes of the treatment was the body weight gain. Six children increased by $50 \%$ the body weight comparing to the expected weight gain when untreated. In the other patients the body weight was stable or decreased [84]. Some interesting results on the cardiovascular system protection were also reported [85]. Nevertheless, HGPS patients presented many side effects related to the molecule. Another therapeutic strategy tested in clinical trials was a combination of two drugs: pravastatin (Pra) an inhibitor of HMG-CoA reductase and an aminobisphosphonate (Zo) an inhibitor of farnesyl-pyrophophate synthase
$[47,54,59]$. The advantage of ZoPra is the reduction of both farnesylation and geranyl-geranylation of progerin avoiding the alternative prenylation induced by farnesyl transferase inhibitors [54,59]. This clinical trial was performed in 12 HGPS patients from 2008 to 2013 in Europe (ClinicalTrials.gov identifier: NCT00731016); however the results of this clinical trial were not published yet. Another therapeutic trial is currently in progress in Boston combining ZoPra and Lonafarnib (ClinicalTrials.gov identifier: NCT00916747). The estimated number of patients is 45 children and it is expected to end in June 2017. Nevertheless, no in vivo studies were performed to evaluate the efficacy and the side effects of this triple drug combination [59]. Despite these advances, further therapeutic platforms are needed o treat this disease.

HGPS iPSCs are very important to recapitulate many aspects of HGPS disease in a dish but also for the understanding of the aging process in humans. This technology allows the generation of cell models that mimic the aging process in humans within a very short period of time [86]. Therefore, novel mechanistic clues and therapies for physiological human aging are now possible.

\section{Acknowledgments}

This work was supported by Fundação para a Ciência e a Tecnologia (PTDC/SAU-TOX/121887/2010; SFRH/BD/71042/2010; SFRH/BD/51678/2011; SFRH/BPD/79323/2011) and COMPETE funding (Project "Stem cell based platforms for Regenerative and Therapeutic Medicine”, Centro-07-ST24-FEDER-002008). The authors declare no conflict of interest to disclose.

\section{Transparency document}

Transparency document related to this article can be found online at http://dx.doi.org/10.1016/j.bbrc.2015.10.014.

\section{References}

[1] J.T. Dimos, K.T. Rodolfa, K.K. Niakan, L.M. Weisenthal, H. Mitsumoto, W. Chung, G.F. Croft, G. Saphier, R. Leibel, R. Goland, H. Wichterle, C.E. Henderson, K. Eggan, Induced pluripotent stem cells generated from patients with ALS can be differentiated into motor neurons, Science 321 (2008) $1218-1221$.

[2] I.-H. Park, N. Arora, H. Huo, N. Maherali, T. Ahfeldt, A. Shimamura, M.W. Lensch, C. Cowan, K. Hochedlinger, G.Q. Daley, Disease-specific induced pluripotent stem cells, Cell 134 (2008) 877-886.

[3] R. McKernan, F.M. Watt, What is the point of large-scale collections of human induced pluripotent stem cells? Nat. Biotechnol. 31 (2013) 875-877.

[4] M. Grskovic, A. Javaherian, B. Strulovici, G.Q. Daley, Induced pluripotent stem cells-opportunities for disease modelling and drug discovery, Nat. Rev. Drug Discov. 10 (2011) 915-929.

[5] J.L. Sterneckert, P. Reinhardt, H.R. Scholer, Investigating human disease using stem cell models, Nat. Rev. Genet. 15 (2014) 625-639.

[6] A. Moretti, K.L. Laugwitz, T. Dorn, D. Sinnecker, C. Mummery, Pluripotent stem cell models of human heart disease, Cold Spring Harb. Perspect. Med. 3 (2013).

[7] J.J. Savla, B.C. Nelson, C.N. Perry, E.D. Adler, Induced pluripotent stem cells for the study of cardiovascular disease, J. Am. Coll. Cardiol. 64 (2014) 512-519.

[8] A. Tanaka, S. Yuasa, K. Node, K. Fukuda, Cardiovascular Disease Modeling Using Patient-Specific Induced Pluripotent Stem Cells, Int. J. Mol. Sci. 16 (2015) 18894-18922.

[9] C. Cheung, A.S. Bernardo, M.W.B. Trotter, R.A. Pedersen, S. Sinha, Generation of human vascular smooth muscle subtypes provides insight into embryologica origin-dependent disease susceptibility, Nat. Biotechnol. 30 (2012) 165-173.

[10] V.V. Orlova, Y. Drabsch, C. Freund, S. Petrus-Reurer, F.E. van den Hil, S. Muenthaisong, P.T. Dijke, C.L. Mummery, Functionality of endothelial cells and pericytes from human pluripotent stem cells demonstrated in cultured vascular plexus and zebrafish xenografts, Arterioscler. Thromb. Vasc. Biol. 34 (2014) 177-186.

[11] A.J. Rufaihah, N.F. Huang, J. Kim, J. Herold, K.S. Volz, T.S. Park, J.C. Lee E.T. Zambidis, R. Reijo-Pera, J.P. Cooke, Human induced pluripotent stem cellderived endothelial cells exhibit functional heterogeneity, Am. J. Transl. Res. 5 (2013) $21-35$.

[12] A. Ditadi, C.M. Sturgeon, J. Tober, G. Awong, M. Kennedy, A.D. Yzaguirre, L. Azzola, E.S. Ng, E.G. Stanley, D.L. French, X. Cheng, P. Gadue, N.A. Speck A.G. Elefanty, G. Keller, Human definitive haemogenic endothelium and arterial vascular endothelium represent distinct lineages, Nat. Cell Biol. 17 
(2015) 580-591.

[13] C. Patsch, L. Challet-Meylan, E.C. Thoma, E. Urich, T. Heckel, J.F. O'Sullivan, S.J. Grainger, F.G. Kapp, L. Sun, K. Christensen, Y. Xia, M.H. Florido, W. He, W. Pan, M. Prummer, C.R. Warren, R. Jakob-Roetne, U. Certa, R. Jagasia, P.O. Freskgard, I. Adatto, D. Kling, P. Huang, L.I. Zon, E.L. Chaikof, R.E. Gerszten M. Graf, R. Iacone, C.A. Cowan, Generation of vascular endothelial and smooth muscle cells from human pluripotent stem cells, Nat. Cell Biol. 17 (2015) 994-1003.

[14] N.M. Kane, Q. Xiao, A.H. Baker, Z. Luo, O. Xu, C. Emanueli, Pluripotent stem cell differentiation into vascular cells: a novel technology with promises for vascular re(generation), Pharmacol. Ther. 129 (2011) 29-49.

[15] D. James, H.S. Nam, M. Seandel, D. Nolan, T. Janovitz, M. Tomishima, L. Studer G. Lee, D. Lyden, R. Benezra, N. Zaninovic, Z. Rosenwaks, S.Y. Rabbany, S. Rafii, Expansion and maintenance of human embryonic stem cell-derived endothelial cells by TGFbeta inhibition is Id1 dependent, Nat. Biotechnol. 28 (2010) $161-166$.

[16] C.M. Metallo, M.A. Vodyanik, J.J. de Pablo, I.I. Slukvin, S.P. Palecek, The response of human embryonic stem cell-derived endothelial cells to shear stress, Biotechnol. Bioeng. 100 (2008) 830-837.

[17] T. Masumura, K. Yamamoto, N. Shimizu, S. Obi, J. Ando, Shear stress increases expression of the arterial endothelial marker EphrinB2 in Murine ES cells via the VEGF-notch signaling pathways, Arterioscler. Thromb. Vasc. Biol. 29 (2009) 2125-2131.

[18] A. Sivarapatna, M. Ghaedi, A.V. Le, J.J. Mendez, Y. Qyang, L.E. Niklason, Arterial specification of endothelial cells derived from human induced pluripotent stem cells in a biomimetic flow bioreactor, Biomaterials 53 (2015) 621-633.

[19] Y. Wang, J. Hu, J. Jiao, Z. Liu, Z. Zhou, C. Zhao, L.J. Chang, Y.E. Chen, P.X. Ma, B. Yang, Engineering vascular tissue with functional smooth muscle cells derived from human iPS cells and nanofibrous scaffolds, Biomaterials 35 (2014) 8960-8969.

[20] C. Xie, J. Hu, H. Ma, J. Zhang, L.-J. Chang, Y.E. Chen, P.X. Ma, Three-dimensional growth of iPS cell-derived smooth muscle cells on nanofibrous scaffolds, Biomaterials 32 (2011) 4369-4375.

[21] H. Zhang, Z.M. Xiong, K. Cao, Mechanisms controlling the smooth muscle cel death in progeria via down-regulation of poly(ADP-ribose) polymerase 1, Proc. Natl. Acad. Sci. U. S. A. 111 (2014) E2261-E2270.

[22] J. Zhang, Q. Lian, G. Zhu, F. Zhou, L. Sui, C. Tan, R.A. Mutalif, R. Navasankari, Y. Zhang, H.F. Tse, C.L. Stewart, A. Colman, A human iPSC model of Hutchinson Gilford Progeria reveals vascular smooth muscle and mesenchymal stem cell defects, Cell Stem Cell 8 (2011) 31-45.

[23] X. Nissan, S. Blondel, C. Navarro, Y. Maury, C. Denis, M. Girard, C. Martinat, A. De Sandre-Giovannoli, N. Levy, M. Peschanski, Unique preservation of neural cells in Hutchinson- Gilford progeria syndrome is due to the expression of the neural-specific miR-9 microRNA, Cell Rep. 2 (2012) 1-9.

[24] L. Yang, M.H. Soonpaa, E.D. Adler, T.K. Roepke, S.J. Kattman, M. Kennedy, E. Henckaerts, K. Bonham, G.W. Abbott, R.M. Linden, L.J. Field, G.M. Keller, Human cardiovascular progenitor cells develop from a KDR + embryonicstem-cell-derived population, Nature 453 (2008) 524-528.

[25] L.S. Ferreira, S. Gerecht, H.F. Shieh, N. Watson, M.A. Rupnick, S.M. Dallabrida, G. Vunjak-Novakovic, R. Langer, Vascular progenitor cells isolated from human embryonic stem cells give rise to endothelial and smooth muscleâ€"like cells and form vascular networks in vivo, Circulation Res. 101 (2007) 286-294.

[26] H. Vazão, R.P.d. Neves, M. Grãos, L. Ferreira, Towards the Maturation and Characterization of Smooth Muscle Cells Derived from Human Embryonic Stem Cells, PLoS One 6 (2011) e17771.

[27] M. Costa, K. Sourris, S.M. Lim, Q.C. Yu, C.E. Hirst, H.C. Parkington, V.J. Jokubaitis, A.E. Dear, H.B. Liu, S.J. Micallef, K. Koutsis, A.G. Elefanty, E.G. Stanley, Derivation of endothelial cells from human embryonic stem cells in fully defined medium enables identification of lysophosphatidic acid and platelet activating factor as regulators of eNOS localization, Stem Cell Res. 10 (2013) 103-117.

[28] P. Zhang, J. Li, Z. Tan, C. Wang, T. Liu, L. Chen, J. Yong, W. Jiang, X. Sun, L. Du, M. Ding, H. Deng, Short-term BMP-4 treatment initiates mesoderm induction in human embryonic stem cells, Blood 111 (2008) 1933-1941.

[29] O. Goldman, O. Feraud, J. Boyer-Di Ponio, C. Driancourt, D. Clay, M.-C. Le Bousse-Kerdiles, A. Bennaceur-Griscelli, G. Uzan, A Boost of BMP4 Accelerates the Commitment of Human Embryonic Stem Cells to the Endothelial Lineage, Stem Cells 27 (2009) 1750-1759.

[30] J.-T. Chi, H.Y. Chang, G. Haraldsen, F.L. Jahnsen, O.G. Troyanskaya, D.S. Chang Z. Wang, S.G. Rockson, M. van de Rijn, D. Botstein, P.O. Brown, Endothelial cell diversity revealed by global expression profiling, Proc. Natl. Acad. Sci. 100 (2003) 10623-10628.

[31] K.L. Marcelo, L.C. Goldie, K.K. Hirschi, Regulation of endothelial cell differentiation and specification, Circ. Res. 112 (2013) 1272-1287.

[32] F. le Noble, D. Moyon, L. Pardanaud, L. Yuan, V. Djonov, R. Matthijsen, C. Breant, V. Fleury, A. Eichmann, Flow regulates arterial-venous differentiation in the chick embryo yolk sac, Development 131 (2004) 361-375.

[33] A.J. Rufaihah, N.F. Huang, J. Kim, J. Herold, K.S. Volz, T.S. Park, J.C. Lee, E.T. Zambidis, R. Reijo-Pera, J.P. Cooke, Human induced pluripotent stem cellderived endothelial cells exhibit functional heterogeneity, Am. J. Transl. Res. 5 (2013) 21-35.

[34] W.C. Aird, Phenotypic Heterogeneity of the Endothelium: II. Representative Vascular Beds, Circulation Res. 100 (2007) 174-190.

[35] C.M. Metallo, M.A. Vodyanik, J.J. de Pablo, I.I. Slukvin, S.P. Palecek, The response of human embryonic stem cell-derived endothelial cells to shear stress, Biotechnol. Bioeng. 100 (2008) 830-837.

[36] W.J. Adams, Y. Zhang, J. Cloutier, P. Kuchimanchi, G. Newton, S. Sehrawat, W.C. Aird, T.N. Mayadas, F.W. Luscinskas, G. Garcia-Cardena, Functional vascular endothelium derived from human induced pluripotent stem cells, Stem Cell Rep. 1 (2013) 105-113.

[37] A.W.G.o.M.o.P. Disease, P.S. Kishnani, R.D. Steiner, D. Bali, K. Berger, B.J. Byrne, L.E. Case, J.F. Crowley, S. Downs, R.R. Howell, R.M. Kravitz, J. Mackey, D. Marsden, A.M. Martins, D.S. Millington, M. Nicolino, G. O'Grady, M.C. Patterson, D.M. Rapoport, A. Slonim, C.T. Spencer, C.J. Tifft, M.S. Watson, Pompe disease diagnosis and management guideline, Genet. Med. 8 (2006) $267-288$.

[38] L.P. Winkel, J.H. Kamphoven, H.J. van den Hout, L.A. Severijnen, P.A. van Doorn, A.J. Reuser, A.T. van der Ploeg, Morphological changes in muscle tissue of patients with infantile Pompe's disease receiving enzyme replacement therapy, Muscle Nerve 27 (2003) 743-751.

[39] J.M. Anneser, D.E. Pongratz, T. Podskarbi, Y.S. Shin, B.G. Schoser, Mutations in the acid alpha-glucosidase gene (M. Pompe) in a patient with an unusual phenotype, Neurology 64 (2005) 368-370.

[40] H.P. Huang, P.H. Chen, W.L. Hwu, C.Y. Chuang, Y.H. Chien, L. Stone, C.L. Chien, L.T. Li, S.C. Chiang, H.F. Chen, H.N. Ho, C.H. Chen, H.C. Kuo, Human Pompe disease-induced pluripotent stem cells for pathogenesis modeling, drug testing and disease marker identification, Hum. Mol. Genet. 20 (2011) $4851-4864$.

[41] T. Higuchi, S. Kawagoe, M. Otsu, Y. Shimada, H. Kobayashi, R. Hirayama, K. Eto, H. Ida, T. Ohashi, H. Nakauchi, Y. Eto, The generation of induced pluripotent stem cells (iPSCs) from patients with infantile and late-onset types of Pompe disease and the effects of treatment with acid-alpha-glucosidase in Pompe's iPSCs, Mol. Genet. Metab. 112 (2014) 44-48.

[42] X. Ge, Y. Ren, O. Bartulos, M.Y. Lee, Z. Yue, K.Y. Kim, W. Li, PJ. Amos, E.C. Bozkulak, A. Iyer, W. Zheng, H. Zhao, K.A. Martin, D.N. Kotton, G. Tellides, I.H. Park, L. Yue, Y. Qyang, Modeling supravalvular aortic stenosis syndrome with human induced pluripotent stem cells, Circulation 126 (2012) 1695-1704.

[43] D.Y. Li, B. Brooke, E.C. Davis, R.P. Mecham, L.K. Sorensen, B.B. Boak E. Eichwald, M.T. Keating, Elastin is an essential determinant of arterial morphogenesis, Nature 393 (1998) 276-280.

[44] C. Kinnear, W.Y. Chang, S. Khattak, A. Hinek, T. Thompson, D. de Carvalho Rodrigues, K. Kennedy, N. Mahmut, P. Pasceri, W.L. Stanford, J. Ellis, S. Mital, Modeling and rescue of the vascular phenotype of Williams-Beuren syndrome in patient induced pluripotent stem cells, Stem Cells Transl. Med. 2 (2013) $2-15$.

[45] J. Hutchinson, Congenital absence of hair and mammary glands with atrophic condition of the skin and its appendages, in a boy whose mother had been almost wholly bald from Alopecia areata from the age of six, Med. Chir. Trans. 69 (1886) 473-477.

[46] H. Gilford, On a condition of mixed premature and immature development, Med. Chir. Trans. 80 (1897), 17-46 25.

[47] X. Nissan, S. Blondel, M. Peschanski, In vitro pathological modelling using patient-specific induced pluripotent stem cells: the case of progeria, Biochem. Soc. Trans. 39 (2011) 1775-1779.

[48] J.-H. Baek, T.s. McKenna, M. Eriksson, Hutchinson-Gilford Progeria Syndrome, Genet. Disord. (2013) 65-87.

[49] R.C. Hennekam, Hutchinson-Gilford progeria syndrome: review of the phenotype, Am. J. Med. Genet. A 140 (2006) 2603-2624.

[50] L.B. Gordon, PRF by the Numbers, The Progeria Research Foundation, 2015.

[51] M. Olive, I. Harten, R. Mitchell, J.K. Beers, K. Djabali, K. Cao, M.R. Erdos, C. Blair B. Funke, L. Smoot, M. Gerhard-Herman, JT. Machan, R. Kutys, R. Virmani, F.S. Collins, T.N. Wight, E.G. Nabel, L.B. Gordon, Cardiovascular pathology in Hutchinson-Gilford progeria: correlation with the vascular pathology of aging, Arterioscler. Thromb. Vasc. Biol. 30 (2010) 2301-2309.

[52] B.C. Capell, F.S. Collins, E.G. Nabel, Mechanisms of cardiovascular disease in accelerated aging syndromes, Circ. Res. 101 (2007) 13-26.

[53] A.M. Aliper, A.B. Csoka, A. Buzdin, T. Jetka, S. Roumiantsev, A. Moskalev, A. Zhavoronkov, Signaling pathway activation drift during aging: HutchinsonGilford Progeria Syndrome fibroblasts are comparable to normal middle-age and old-age cells, Aging (Albany NY) 7 (2015) 26-37.

[54] L. Trigueros-Motos, J.M. Gonzalez, J. Rivera, V. Andres, Hutchinson-Gilford progeria syndrome, cardiovascular disease and oxidative stress, Front. Biosci. Sch. Ed. 3 (2011) 1285-1297.

[55] L.B. Gordon, The premature aging syndrome Hutchinson-Gilford Progeria Syndrome: insights into normal aging, in: K.R.H.M. Fillit, K. Woodhouse (Eds.), Geriatric Medicine and Gerontology, 2010, pp. 66-72.

[56] S. Pereira, P. Bourgeois, C. Navarro, V. Esteves-Vieira, P. Cau, A. De SandreGiovannoli, N. Levy, HGPS and related premature aging disorders: from genomic identification to the first therapeutic approaches, Mech. Ageing Dev. 129 (2008) 449-459.

[57] P. Scaffidi, T. Misteli, Lamin A-dependent nuclear defects in human aging, Science 312 (2006) 1059-1063.

[58] R.L. Pollex, R.A. Hegele, Hutchinson-Gilford progeria syndrome, Clin. Genet. 66 (2004) 375-381.

[59] P. Cau, C. Navarro, K. Harhouri, P. Roll, S. Sigaudy, E. Kaspi, S. Perrin, A. De Sandre-Giovannoli, N. Levy, Nuclear matrix, nuclear envelope and premature aging syndromes in a translational research perspective, Semin. Cell Dev. Biol. 29 (2014) 125-137. 
[60] F. Coppedè, Premature aging syndrome, in: S.I. Ahmad (Ed.), Neurodegenerative Diseases, Springer, US, 2012, pp. 317-331.

[61] M. Gerhard-Herman, L.B. Smoot, N. Wake, M.W. Kieran, M.E. Kleinman, D.T. Miller, A. Schwartzman, A. Giobbie-Hurder, D. Neuberg, L.B. Gordon, Mechanisms of premature vascular aging in children with Hutchinson-Gilford progeria syndrome, Hypertension 59 (2012) 92-97.

[62] W.E. Stehbens, B. Delahunt, T. Shozawa, E. Gilbert-Barness, Smooth muscle cell depletion and collagen types in progeric arteries, Cardiovasc Pathol. 10 (2001) 133-136.

[63] B.C. Capell, F.S. Collins, Human laminopathies: nuclei gone genetically awry, Nat. Rev. Genet. 7 (2006) 940-952.

[64] Y. Gruenbaum, A. Margalit, R.D. Goldman, D.K. Shumaker, K.L. Wilson, The nuclear lamina comes of age, Nat. Rev. Mol. Cell Biol. 6 (2005) 21-31.

[65] A. De Sandre-Giovannoli, R. Bernard, P. Cau, C. Navarro, J. Amiel, I. Boccaccio, S. Lyonnet, C.L. Stewart, A. Munnich, M. Le Merrer, N. Levy, Lamin a truncation in Hutchinson-Gilford progeria, Science 300 (2003) 2055.

[66] M. Eriksson, W.T. Brown, L.B. Gordon, M.W. Glynn, J. Singer, L. Scott, M.R. Erdos, C.M. Robbins, T.Y. Moses, P. Berglund, A. Dutra, E. Pak, S. Durkin, A.B. Csoka, M. Boehnke, T.W. Glover, F.S. Collins, Recurrent de novo point mutations in lamin A cause Hutchinson-Gilford progeria syndrome, Nature 423 (2003) 293-298.

[67] C.J. Reddel, A.S. Weiss, Lamin A expression levels are unperturbed at the normal and mutant alleles but display partial splice site selection in Hutchinson-Gilford progeria syndrome, J. Med. Genet. 41 (2004) 715-717.

[68] B.W. Gordon LB, F.S. Collins, Hutchinson-Gilford Progeria Syndrome, 2003.

[69] H.C. Dietz, New therapeutic approaches to mendelian disorders, N. Engl. J. Med. 363 (2010) 852-863.

[70] D.E. Vazquez, D.F. Nino, A. De Maio, D.M. Cauvi, Sustained expression of lipocalin-2 during polymicrobial sepsis, Innate Immun. 21 (2014) 477-489.

[71] R.D. Goldman, D.K. Shumaker, M.R. Erdos, M. Eriksson, A.E. Goldman, L.B. Gordon, Y. Gruenbaum, S. Khuon, M. Mendez, R. Varga, F.S. Collins, Accumulation of mutant lamin A causes progressive changes in nuclear architecture in Hutchinson-Gilford progeria syndrome, Proc. Natl. Acad. Sci. U. S. A. 101 (2004) 8963-8968.

[72] L.B. Gordon, F.G. Rothman, C. Lopez-Otin, T. Misteli, Progeria: a paradigm for translational medicine, Cell 156 (2014) 400-407.

[73] G.H. Liu, B.Z. Barkho, S. Ruiz, D. Diep, J. Ou, S.L. Yang, A.D. Panopoulos, K. Suzuki, L. Kurian, C. Walsh, J. Thompson, S. Boue, H.L. Fung, I. SanchoMartinez, K. Zhang, J. Yates 3rd, J.C. Izpisua Belmonte, Recapitulation of premature ageing with iPSCs from Hutchinson-Gilford progeria syndrome, Nature 472 (2011) 221-225.

[74] J.C. Ho, T. Zhou, W.H. Lai, Y. Huang, Y.C. Chan, X. Li, N.L. Wong, Y. Li, K.W. Au, D. Guo, J. Xu, C.W. Siu, D. Pei, H.F. Tse, M.A. Esteban, Generation of induced pluripotent stem cell lines from 3 distinct laminopathies bearing heterogeneous mutations in lamin A/C, Aging (Albany NY) 3 (2011) 380-390.

[75] L.J. Niedernhofer, J.C. Glorioso, P.D. Robbins, Dedifferentiation rescues senescence of progeria cells but only while pluripotent, Stem Cell Res. Ther. 2 (2011) 28.
[76] J.M. Freije, C. Lopez-Otin, Reprogramming aging and progeria, Curr. Opin. Cel Biol. 24 (2012) 757-764.

[77] D. Constantinescu, H.L. Gray, P.J. Sammak, G.P. Schatten, A.B. Csoka, Lamin A/C expression is a marker of mouse and human embryonic stem cell differentiation, Stem Cells 24 (2006) 177-185.

[78] Z.M. Xiong, C. LaDana, D. Wu, K. Cao, An inhibitory role of progerin in the gene induction network of adipocyte differentiation from iPS cells, Aging (Albany NY) 5 (2013) 288-303.

[79] C.Y. Lo, Y.W. Tjong, J.C. Ho, C.W. Siu, S.Y. Cheung, N.L. Tang, S. Yu, H.F. Tse, $X$. Yao, An upregulation in the expression of vanilloid transient potential channels 2 enhances hypotonicity-induced cytosolic $\mathrm{Ca}(2)(+)$ rise in human induced pluripotent stem cell model of Hutchinson-Gillford Progeria, PLoS One 9 (2014) e87273.

[80] H.J. Jung, C. Coffinier, Y. Choe, A.P. Beigneux, B.S. Davies, S.H. Yang R.H. Barnes 2nd, J. Hong, T. Sun, S.J. Pleasure, S.G. Young, L.G. Fong, Regulation of prelamin A but not lamin C by miR-9, a brain-specific microRNA, Proc. Natl. Acad. Sci. U. S. A. 109 (2012) E423-E431.

[81] B.C. Capell, M.R. Erdos, J.P. Madigan, J.J. Fiordalisi, R. Varga, K.N. Conneely, L.B. Gordon, C.J. Der, A.D. Cox, F.S. Collins, Inhibiting farnesylation of progerin prevents the characteristic nuclear blebbing of Hutchinson-Gilford progeria syndrome, Proc. Natl. Acad. Sci. U. S. A. 102 (2005) 12879-12884.

[82] S. Blondel, A.L. Jaskowiak, A.L. Egesipe, A. Le Corf, C. Navarro, V. Cordette C. Martinat, Y. Laabi, K. Djabali, A. de Sandre-Giovannoli, N. Levy, M. Peschanski, X. Nissan, Induced pluripotent stem cells reveal functiona differences between drugs currently investigated in patients with hutchinson-gilford progeria syndrome, Stem Cells Transl. Med. 3 (2014) 510-519.

[83] G.-H. Liu, K. Suzuki, J. Qu, I. Sancho-Martinez, F. Yi, M. Li, S. Kumar, E. Nivet J. Kim, R.D. Soligalla, I. Dubova, A. Goebl, N. Plongthongkum, H.-L. Fung K. Zhang, J.F. Loring, L.C. Laurent, J.C.I. Belmonte, Targeted Gene Correction of laminopathy-associated LMNA mutations in patient-specific iPSCs, Cell Stem cell 8 (2011) 688-694.

[84] L.B. Gordon, M.E. Kleinman, D.T. Miller, D.S. Neuberg, A. Giobbie-Hurder M. Gerhard-Herman, L.B. Smoot, C.M. Gordon, R. Cleveland, B.D. Snyder B. Fligor, W.R. Bishop, P. Statkevich, A. Regen, A. Sonis, S. Riley, C. Ploski, A. Correia, N. Quinn, N.J. Ullrich, A. Nazarian, M.G. Liang, S.Y. Huh, A. Schwartzman, M.W. Kieran, Clinical trial of a farnesyltransferase inhibitor in children with Hutchinson-Gilford progeria syndrome, Proc. Natl. Acad. Sci. U. S. A. 109 (2012) 16666-16671.

[85] J. Couzin-Frankel, Medicine. Drug trial offers uncertain start in race to save children with progeria, Science 337 (2012) 1594-1595.

[86] G.H. Liu, Z. Ding, J.C. Izpisua Belmonte, iPSC technology to study human aging and aging-related disorders, Curr. Opin. Cell Biol. 24 (2012) 765-774.

[87] O. Dreesen, C.L. Stewart, Accelerated aging syndromes, are they relevant to normal human aging? Aging (Albany NY) 3 (2011) 889-895.

[88] K.Z. Al-Shali, R.A. Hegele, Laminopathies and atherosclerosis, Arterioscler. Thromb. Vasc. Biol. 24 (2004) 1591-1595. 